\title{
Synthesis of multicomponent metallic layers during impulse plasma deposition
}

\author{
KATARZYNA NOWAKOWSKA-LANGIER ${ }^{1 *}$, RAFAL CHOdUn $^{2}$, KRZYSZTOF ZdUNEK $^{2}$ \\ ${ }^{1}$ Material Physics Department, National Centre for Nuclear Research, A. Soltana 7, 05-400 Otwock-Swierk, Poland \\ ${ }^{2}$ Faculty of Materials Science and Engineering, Warsaw University of Technology, Woloska 141, 02-507 Warsaw, Poland
}

\begin{abstract}
Pulsed plasma in the impulse plasma deposition (IPD) synthesis is generated in a coaxial accelerator by strong periodic electrical pulses, and it is distributed in a form of energetic plasma packets. A nearly complete ionization of gas, in these conditions of plasma generation, favors the nucleation of new phase of ions and synthesis of metastable materials in a form of coatings which are characterized by amorphous and/or nanocrystalline structure. In this work, the $\mathrm{Fe}-\mathrm{Cu}$ alloy, which is immiscible in the state of equilibrium, was selected as a model system to study the possibility of formation of a non-equilibrium phase during the IPD synthesis. Structural characterization of the layers was done by means of X-ray diffraction and conversionelectron Mössbauer spectroscopy. It was found that supersaturated solid solutions were created as a result of mixing and/or alloying effects between the layer components delivered to the substrate independently and separately in time. Therefore, the solubility in the $\mathrm{Fe}-\mathrm{Cu}$ system was largely extended in relation to the equilibrium conditions, as described by the equilibrium phase diagram in the solid state.
\end{abstract}

Keywords: Fe-Cu alloy; metastable alloys; nanocrystalline films; physical vapor deposition (PVD); impulse plasma deposition (IPD)

(C) Wroclaw University of Technology.

\section{Introduction}

Pulsed plasma generated in a coaxial plasma accelerator in impulse plasma deposition (IPD), is the only source of mass and energy during the entire deposition process [1]. This "single-source" character of deposition ensures that a special close relation exists between the parameters of IPD process and the characteristics of the layers (morphology, phase/chemical composition, growth kinetics, adhesion) [1]. Plasma (ejected to the vacuum chamber toward the substrate) is emitted from a coaxial accelerator in a form of a plasmoid, which is accelerated by a magnetic pressure to a speed of about $10^{4} \mathrm{~m} \cdot \mathrm{s}^{-1}$ and lifetime of the order of $10^{-4} \mathrm{~s}$. Application of pulsed plasma offers new possibilities of influencing material parameters, such as morphology (crystallites size) or phase structure (to establish unique metastable, non-equilibrium phases), even at a relatively low temperature of

*E-mail: k.nowakowska-langier@ncbj.gov.pl the substrate (far from equilibrium conditions). Our previous research showed that the IPD method enabled us to produce alloys characterized by a non-equilibrium structure of, e.g. $\operatorname{MCrAl}(\mathrm{Y})$ [2] or $\mathrm{Fe}-\mathrm{Ti}$ [3] type. Achieving a metastable product of IPD synthesis is possible due to so-called "clusterlike" layer growth mechanism, which consists in limited coalescence of clusters formed in plasma itself as a result of homogeneous nucleation of ions $[4,5]$ which are delivered onto the cold surface of the substrate [1]. As reported by Sokolowska et al. [6], the size of the clusters, immediately after their formation in the impulse plasma, was of about $0.7 \mathrm{~nm}$. It was found that the layer produced by IPD was chiefly formed just from these particles. Their condensation took place on the surface of the substrate, whose thermal state was characterized by the presence of an instantaneous temperature (with duration of a single pulse of plasma) and a quasistationary component which represented the heat accumulated in the substrate material during the IPD process. 
According to Zdunek [7], after exposure for pulsed plasma for a long time, the initially cold substrate may reach the maximum temperature of $500 \mathrm{~K}$. However, during the synthesis, the kinetic energy of plasmoids is dissipated upon the substrate surface and causes a pulsed heating of a near surface region to a temperature reaching even $2000 \mathrm{~K}[1,6]$ (the only source of heat in the IPD process).

The migrating particles collide with one another and undergo limited coalescence and agglomeration. As a result of this growth mechanism, the layer has mostly a nanocrystalline or amorphous/nanocrystalline morphology (depending on the energetic parameters of impulse plasma generation during the IPD) $[3,6,8,9]$ and, therefore, the phase composition of the layer material synthesized by the IPD is dependent on the atomic mixing effect caused by the heating effect $[8,10]$.

Understanding the creation of non-equilibrium alloys of immiscible elements is clearly under a considerable scientific and technological interest. $\mathrm{The} \mathrm{Fe}-\mathrm{Cu}$ system is an example in this regard. Under the equilibrium conditions, as described by the equilibrium phase diagram [11], the $\mathrm{Fe}-\mathrm{Cu}$ system consists of two components $(\mathrm{Fe}$ and $\mathrm{Cu}$ ) that are characterized by the lack of mutual solubility in the solid state because of the relatively high positive enthalpy of mixing $[12,13]$. Thus, equilibrium in the solid state is characterized by a twophase structure. The immiscible $\mathrm{Fe}-\mathrm{Cu}$ alloys have been an object of interest of many research groups, and they are well-known and widely studied in the literature [12-25, 31-34]. Therefore, in this work the $\mathrm{Fe}-\mathrm{Cu}$ system is regarded as a good model to study the formation of non-equilibrium phases. Expanded research about the structure of this kind of alloys, prepared by different techniques, is carried out because of the possibility to achieve a variety of new properties, thus, the applications [12-26]. Supersaturated solid solutions are precursors of structures consisting of ferromagnetic/nonmagnetic areas that are required for giant magnetoresistance (GMR). Metastable $\mathrm{Fe}-\mathrm{Cu}$ alloys can be prepared by liquid quenching $[14,15,26]$, electrodeposition [16-18] thermal evaporation [19], sputtering [20-22] or mechanical alloying [5, 6, 14-16]. The structure and the properties of the $\mathrm{Fe}-$ $\mathrm{Cu}$ alloys depend on the production method. Using the characteristic features of the synthesis processes of these methods (e.g. a short time, participation of ions, elastic energy, etc.) there is a chance to effectively expand the range of the existence of single-phase areas in the whole range of the composition $[14,15,26]$.

In this paper, we present the results of formation of non-equilibrium phase structure in the $\mathrm{Fe}-\mathrm{Cu}$ crystalline alloy layers obtained during the impulse plasma deposition (IPD). The $\mathrm{Fe}-\mathrm{Cu}$ alloy is a good example which will help to demonstrate the effects of complex energetic interactions existing during the IPD synthesis.

\section{Experimental}

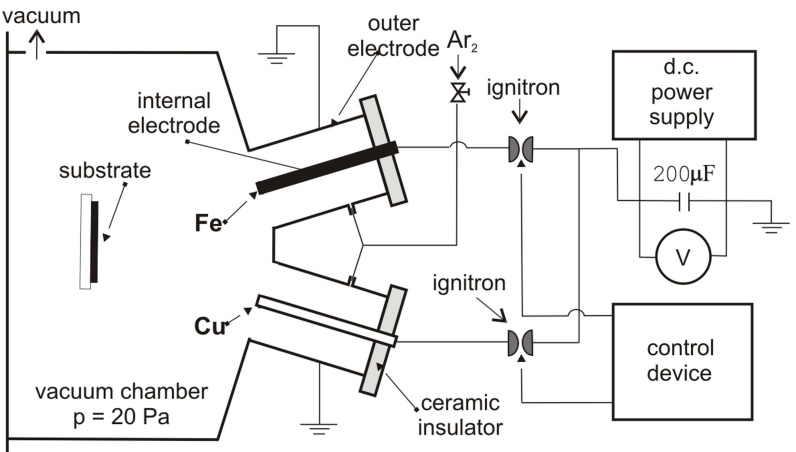

Fig. 1. A schematic view of the IPD apparatus used in experiments for the synthesis of the $\mathrm{Fe}-\mathrm{Cu}$ alloy layers.

The $\mathrm{Fe}-\mathrm{Cu}$ alloy layers were synthesized by impulse plasma deposition (IPD) method. The IPD apparatus was described in detail previously [8, 10]. In our experiments, we used two independently and alternately working accelerators of impulse plasma, mounted in a vacuum chamber. A schematic view of the apparatus used in our experiments is presented in Fig. 1. The internal electrodes of the coaxial accelerators, made of copper and iron, were used as the sources of $\mathrm{Cu}$ and Fe, respectively. The plasma processes were carried out in an argon atmosphere under a dynamic pressure of $20 \mathrm{~Pa}$, with the total number of plasma impulses 
equal to 3000 , resulting in the layer final thickness of a few hundred nanometers. The individual packs of the plasma with a lifetime of about $100 \mathrm{~s}$, which were generated with a specific frequency of the order of $0.33 \mathrm{~Hz}$, were ejected in a form of plasmoids. The plasmoids were accelerated inside the coaxial accelerator by Ampere force and ejected to the substrate surfaces with a velocity of about $10^{4} \mathrm{~m} / \mathrm{s}$. The discharge voltage of the capacitor battery of $200 \mathrm{~F}$ was equal to $3 \mathrm{kV}$. The layers were deposited on a substrate which was not heated from any external heat source before, during and after the deposition of layers (the impulse plasma was the only heat source). The substrates were positioned perpendicular to the plasma accelerator axis, keeping a substrate-accelerator distance of $15 \mathrm{~cm}$.

The control factor in the selection of the composition of the $\mathrm{Fe}-\mathrm{Cu}$ alloy layers was the number of impulses generated by each alternately working accelerator. The successive portions of iron and copper were deposited independently and separately in time. For verification of chemical composition of the alloy layers, EDS analysis was done. The compositions of $\mathrm{Fe}-\mathrm{Cu}$ alloy layers studied in this paper included: 10, 25, 35, 50 and $70 \%$ copper. All compositions were given in atomic percentages.

Structural characterization of the $\mathrm{Fe}-\mathrm{Cu}$ layers was done by means of an X-ray diffractometer by using $\mathrm{CuK} \alpha$ radiation and by conversion electron Mössbauer spectroscopy (CEMS). The CEMS measurements were performed at room temperature. A computer-controlled spectrometer with a 57Co-in-Rh source was used

\section{Results and discussion}

$\mathrm{X}$-ray diffraction patterns of $\mathrm{Fe}-\mathrm{Cu}$ alloy layers obtained by the IPD method are shown in Fig. 2. As one can see, for the Fe-rich layer, only bcc diffraction lines related to iron were recorded. Similarly, in the $\mathrm{Cu}$-rich layer, only fcc diffraction lines corresponding to copper were found. The intensity of the lines changed with the copper contents. Depending on composition, we observed: (a) a coexistence region, where both the bcc and the fcc phases were present, and (b) metastable, single-phase regions.

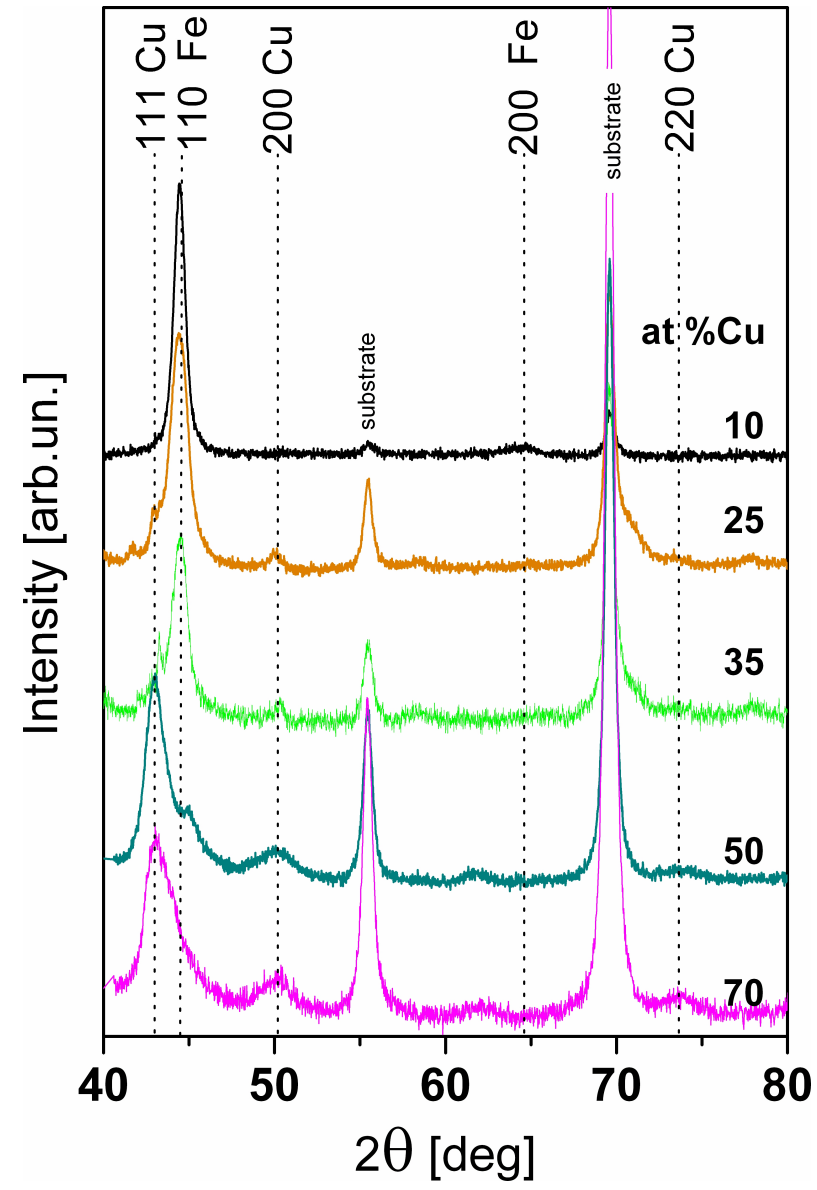

Fig. 2. X-ray diffraction patterns of $\mathrm{Fe}-\mathrm{Cu}$ alloy layers obtained by the impulse plasma deposition method.

The single-phases bcc and fcc were present up to 25 at. $\% \mathrm{Cu}$ and above 50 at. $\% \mathrm{Cu}$, respectively. The phase compositions determined by X-ray diffraction measurements were confirmed by the results of CEMS measurements. Fig. 3 shows CEMS spectra and the corresponding hyperfine field distributions for the $\mathrm{Fe}-\mathrm{Cu}$ alloy layers obtained by IPD method. The Mössbauer spectra were recorded for the layers with copper concentration equal to $10,35,50$ and 70 at.\%. For the $\mathrm{Fe}-\mathrm{Cu}$ layers with 10 at.\% copper, the Mössbauer spectrum is almost identical to those of bcc-Fe. Significant changes are observed in the spectra with increasing $\mathrm{Cu}$ content, where different components can be distinguished: (a) new magnetic sextets with a hyperfine field of about $300 \mathrm{kOe}$ characteristic of the bcc- $\mathrm{Fe}(\mathrm{Cu})$ 
phase, where Fe atoms are surrounded by $\mathrm{Cu}$ atoms and (b) broadened magnetic sextet with a hyperfine field distribution of about 200 to $240 \mathrm{kOe}$.

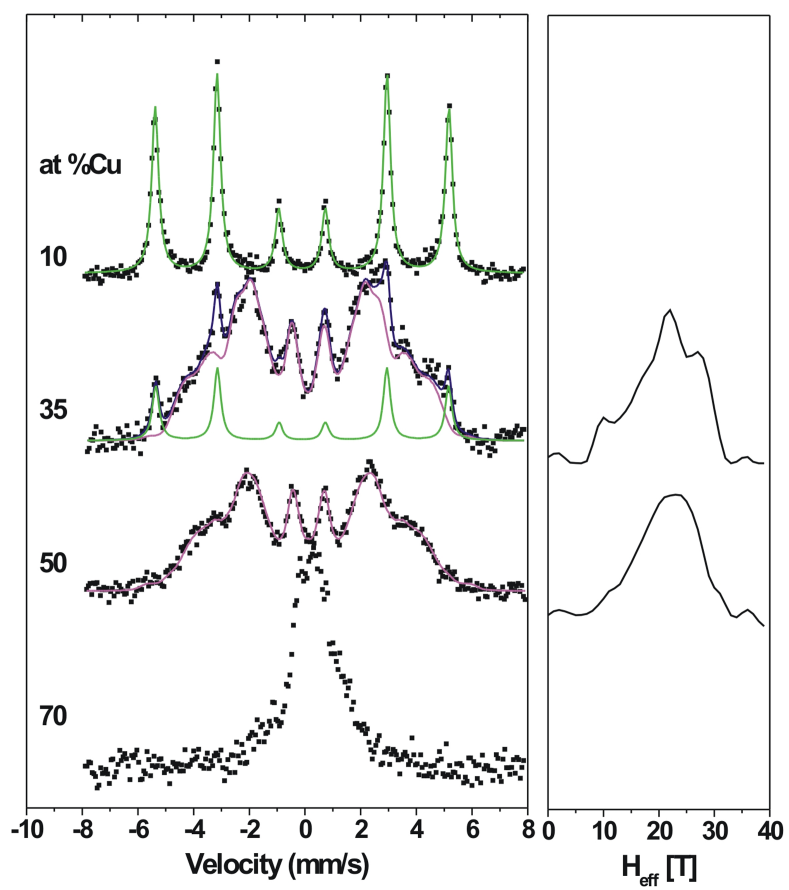

Fig. 3. Room-temperature CEMS spectra and the corresponding hyperfine field distributions for the $\mathrm{Fe}-\mathrm{Cu}$ alloy layers obtained by IPD method.

As reported by Jiang et al. [15], mixing of Fe and $\mathrm{Cu}$ atoms results in formation of paramagnetic doublet and widened magnetic sextet caused by a hyperfine field distribution, which is attributed to the fcc-FeCu solid solution. The hyperfine field can be analyzed in terms of different environments for the iron atoms arising from near neighbors interactions. Deconvolution of such spectrum shows that the distribution of nearest neighbor configurations in the fcc- $\mathrm{FeCu}$ phase follows a binomial distribution, indicating a random solid solution. It means that many different environments of iron atoms exist in the fcc-FeCu solid solution and demonstrates that $\mathrm{Fe}$ and $\mathrm{Cu}$ are alloyed on an atomic level [15]. Therefore, the obtained broadened magnetic sextet for the $\mathrm{Fe}-\mathrm{Cu}$ layer with 35 and 50 at.\% copper does not exclude the presence of the paramagnetic components that are characteristic of the $\mathrm{Fe}-\mathrm{Cu}$ alloy with the same or similar composition [15, 21, 25, 26]. The Mössbauer spectrum of the $\mathrm{Cu}$-rich layers (70 at.\% $\mathrm{Cu}$ ) does not show any evidence of the bcc-Fe, only a paramagnetic peak characteristic of fcc- $\mathrm{Cu}(\mathrm{Fe})$ was found.

In case of the IPD method, the lack of equilibrium phase composition shows that under the conditions of pulsed dosing of mass and energy (in the form of each individual plasmoid), which results in the alternate formation of $\mathrm{Fe}$ and $\mathrm{Cu}$ clusters in plasma itself, intensive mixing occurs between the two components of the coating deposited on the cold substrate surface.

During the IPD deposition process the surface of the substrate is bombarded by the clusters. The problem of cluster interactions with the surface of a substrate has been widely discussed in many studies [27-30]. According to them, the nature of these phenomena depends on the kinetic energy of incident clusters, type and temperature of substrate, cluster size and also the direction of the beam relative to the substrate surface, etc. All these factors affect the rearrangement and diffusion which may occur on substrate surface $[27,28]$. The phases present in the coating material were supersaturated solid solutions of bcc and fcc structure, depending on $\mathrm{Cu}$ content. Both the phases were characterized by increased values of lattice parameters relatively to the pure components of $\mathrm{Fe}$ and $\mathrm{Cu}$, respectively. In the range of approx. 25 to $50 \% \mathrm{Cu}$ content, both of the supersaturated solid solutions were present in the deposited films. The intensive, short-distance diffusion between the neighboring nanoparticles of $\mathrm{Cu}$ and $\mathrm{Fe}$ occurring during IPD synthesis led us to suppose that this mixing was a result of collisions between the product material and energetic cluster particles delivered to the surface layer as a substance of each individual plasmoid [2, 3, 8, 31]. The mechanism of mixing in the case of the IPD could be explained according to the concept proposed by Yavari et al. [24] based on the assumption that ultra small (up to $2 \mathrm{~nm}$ ) metallic grains could be easily dissolved in the matrix which leads to formation of supersaturated systems.

Fig. 4 summarizes the composition dependence of lattice constants for the $\mathrm{Fe}-\mathrm{Cu}$ alloys obtained by different synthesis methods [14-25]. The values obtained in our experiments agree with the data 


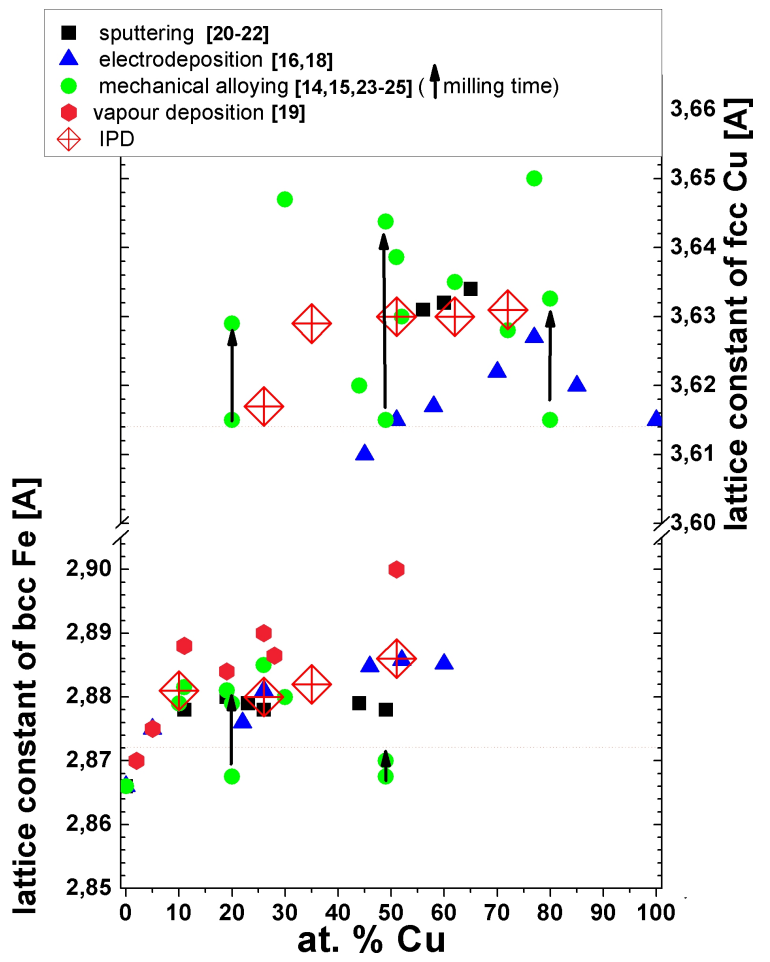

Fig. 4. Lattice parameters of bcc and fcc phases as a function of copper concentration [14-25]. The arrow in the case of mechanical alloying shows changes of lattice parameters caused by the milling time.

reported for $\mathrm{Fe}-\mathrm{Cu}$ alloys prepared by various methods. A schematic diagram of the solid solutions of $\mathrm{Fe}-\mathrm{Cu}$ system (the phase boundary) produced by various methods, compared to the equilibrium phase boundary at room temperature is illustrated in Fig. 5. As one can see, the good results, i.e. the extension of the single-phase zones, especially fcc single-phase zone are achievable in the case of the mechanical alloying method, but also in the case of plasma surface engineering methods.

The present research shows that the IPD method is also successful in the deposition of the metastable structure of alloy layers in a large composition range. The solubility in the $\mathrm{Fe}-\mathrm{Cu}$ system was largely extended. These kinds of alloys can be precursors for a granular mixture of immiscible elements from which giant magnetoresistance can be derived [8]. As reported by Crespo et al. [32, 33], the supersaturated and metastable fcc phases undergo a spinodal decomposition, which

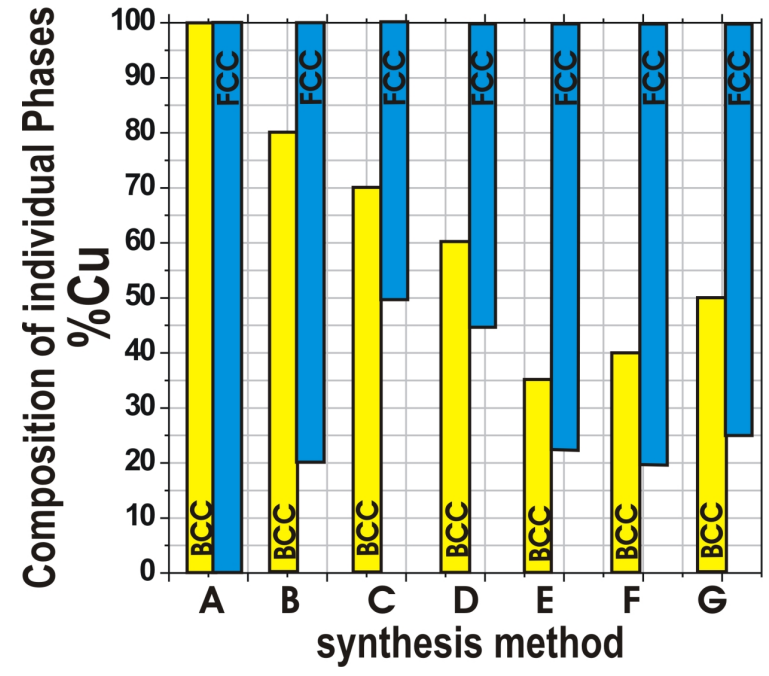

Fig. 5. Metastability regions of the structure of a $\mathrm{Fe}-\mathrm{Cu}$ alloy obtained by different methods supplemented by the results of the present study. Phase boundaries obtained by: (A) equilibrium phase boundary at room temperature [11], (B) liquid quenching [14, 15], (C) vapor deposition [19], (D) electrodeposition [16, 18], (E) sputtering on cryogenic substrates [20], (F) mechanical alloying [23-25], and $(G)$ the IPD method (this work).

finally yields a mixture of fcc and bcc phases. The magnetic properties of the $\mathrm{Fe}-\mathrm{Cu}$ alloy layers were the subject of our earlier studies $[9,34]$.

\section{Conclusion}

In our work, we studied the structure of the $\mathrm{Fe}-\mathrm{Cu}$ alloy layers formed during impulse plasma deposition (IPD) synthesis. The obtained phase structure was characterized by the presence of single-phase supersaturated solid solutions: bcc- $\mathrm{Fe}(\mathrm{Cu})$ in case of the Fe-rich layer and $\mathrm{fcc}-\mathrm{Cu}(\mathrm{Fe})$ in case of the $\mathrm{Cu}$-rich layer, which were formed in these immiscible systems. Singlephases, bcc and fcc, occurred in the $\mathrm{Fe}-\mathrm{Cu}$ layers with a copper content less than about 25 at. $\%$ and with a copper content larger than about 50 at.\%, respectively. The lattice parameters of both the structures were larger than those of pure $\mathrm{Fe}$ and pure $\mathrm{Cu}$. The results of our investigation showed that the phase composition of the layer material 
synthesized by IPD was dependent on the atomic mixing effect between the layer components delivered to the substrate independently and separately in time. The solubility in $\mathrm{Fe}-\mathrm{Cu}$ system was extended relative to the equilibrium state. This demonstrates that the IPD method is successful in producing metastable structures of alloy layers in a large composition range.

\section{Acknowledgements}

This work was supported by the Polish State National Science Centre within the Project 2013/09/B/ST8/02418.

\section{References}

[1] ZduneK K., Surf. Coat. Tech., 201 (2007), 4813.

[2] ZdUnEK K., J. Mater. Sci., 26 (1991), 4433.

[3] Nowakowska-Langier K., ZdUneK K., KopCEWICZ M., Vacuum, 78 (2) (2005), 423.

[4] KashChiEw D., J. Cryst. Growth, 13 - 14 (1972), 128.

[5] Rusanow A., J. Colloid Inter. Sci., 68 (1972), 32.

[6] Sokolowska A., Zdunek K., Grigoriew H., RoMANOWSKI Z., J. Mater. Sci., 21 (1986), 763.

[7] ZdUneK K., Vacuum, 47 (1996), 1437.

[8] NowakowsKa-Langier K., ZduneK K., Wierzbinski E., Surf. Coat. Tech., 204 (2010), 2564.

[9] Nowakowska-Langier K., Zdunek K, Plasma Process. Polym., 6 (2009), S826.

[10] Nowakowska-Langier K., Chodun R., NietUbyc R., Minikayev R., Zdunek K., Appl. Surf. Sci., 275 (2013), 14.

[11] Massalski T.B., Binary Alloy Phase Diagrams, 2nd Edition, ASM International, Metals Park, Ohio, 1991.

[12] Turchanin M.A., Agraval P.G., Nikolaenko I.V., J. Phase Equil. Diff., 24 (2003), 307.

[13] Koziel T., KedZierski Z., Zielinska-Lipiec A., ZIEWIE K., Scripta Mater., 54 (2006), 1991.

[14] Qi M., Zhu M., YAng D.Z., J. Mater. Sci. Lett., 13 (1994), 966.

[15] Jiang J.Z., Gente C., Bormann R., Mat. Sci. Eng. A-Struct., 242 (1998), 268.
[16] Ueda Y., Ikeda S., Mori Y., Zaman H., Mat. Sci. Eng. A-Struct., 217 - 218 (1996), 371.

[17] Umut S., Celalettin Baykul M., Adv. Mater. Sci. Eng., 2013 (2013), 1.

[18] Almasi-Kashi M., Ramazani A., Kheyri F., JAFAri-Khamse E., Mater. Chem. Phys., 144 (2014), 230.

[19] Kneller E.F., J. Appl. Phys., 35 (1964), 2210.

[20] Sumiyama K., Yoshitake T., Nakamura Y., Acta Metall. Sin., 33 (1985), 1785.

[21] Sumiyama K., Nakamura Y., J. Magn. Magn. Mater., 35 (1983), 219.

[22] Chen Y., Liu Y., Sun C., Yu K.Y., Song M., Wang H., ZhANG X., Acta Mater., 60 (2012), 6312.

[23] Uenishi K., Kobayashi K.F., Nasu S., Hatano H., Ishihara K.N., Shingu P.H., Z. Metallkd., 83 (1992), 132.

[24] Yavari A.R., Desre P.J., Benameur T., BeNAMEUR, Phys. Rev. Lett., 68 (1992), 2235.

[25] Majumdar B., Manivel R.M., Narayanasamy A., Chattopadhyay K., J. Alloy. Compd., 248 (1997), 192.

[26] Ma E., Prog. Mater. Sci., 50 (2005), 413.

[27] Zhang S., Gong H., Gao N., Wang Z., Li G., Comp. Mater. Sci., 85 (2014), 230.

[28] Zhang S., Gong H., Chen X., Li G., Wang Z., Appl. Surf. Sci., 314 (2014), 433.

[29] Gong H., Lu W., Wang L., Li G., Zhang S., Comp. Mater. Sci., 65 (2012), 230.

[30] Cattaneo D., Foglio S., Casari C.S., Li Bassi A., Passoni M., Bottani C.E., Surf. Sci., 601 (2007), 1892.

[31] Childress J.R., Chien C.L., Phys. Rev. B, 43 (1991), 8089.

[32] Crespo P., Hernando A., Escorial G.A., Phys. Rev. B, 49 (1994), 3227.

[33] Crespo P., Hernando A., Yavari R., Drbohlav O., Escorial G.A., Phys. Rev. B, 48 (1993), 7134.

[34] NowaKowsKa-LANGIER K., ZdUNEK K., LUCINSKI T., Surf. Coat. Tech., 9 - 11 (2007), 5333.

Received 2015-02-23 Accepted 2015-05-04 